\title{
Sporadic Creutzfeldt-Jakob disease
}

INSERM

\section{Source}

INSERM. (1999). Orphanet: an online rare disease and orphan drug data base. Sporadic Creutzfeldt-jakob disease. ORPHA:204

Sporadic Creutzfeldt-Jakob disease (sCJD) is a subacute fatal neurodeg enerative disease belonging to the group of prion diseases, characterized by a clinical triad of dementia, myoclonus, and EEG anomalies, along with neuropathological evidence of neuronal loss, spongiform changes, and astrocytosis. There are three types of CJD: sporadicCJD (SCJD), inherited CJD (see this term), and iatrogenic and variant CJD (vCJD). 